\title{
Composição centesimal e teste de aceitação e intenção de compra do pintado amazônico (Pseudoplatystoma fasciatum X Leiarius marmoratus) e piauçu (Leporinus macrocephalus)*
}

\section{Proximate composition and acceptance test and buy intention of amazonian pintado (Pseudoplatystoma fasciatum X Leiarius marmoratus) and piauçu (Leporinus macrocephalus)}

\author{
Marilu Lanzarin, ${ }^{* *}$ Daniel Oster Ritter, ${ }^{* *}$ Edivaldo Sampaio de Almeida Filho, ${ }^{* * *}$ \\ Eliane Teixeira Mársico, ${ }^{* * *}$ Mônica Queiroz de Freitas ${ }^{* * * *}$
}

\begin{abstract}
Resumo
O objetivo do trabalho foi caracterizar a composição centesimal e a aceitação e intenção de compra do pintado amazônico (Pseudoplatystoma fasciatum X Leiarius marmoratus) e do piauçu (Leporinus macrocephalus). Foram obtidos seis exemplares do pintado amazônico e oito do piauçu. Analisou-se o conteúdo de umidade, cinzas, proteínas, lipídeos, carboidratos e valor energético. O teste de aceitação foi conduzido utilizando-se escala hedônica de nove pontos e a intenção de compra utilizando uma escala de cinco pontos. Os valores médios de composição centesimal encontrado foram de 74,67\% e 74,90\% para umidade, 0,99\% e $1,16 \%$ de cinzas, $20,49 \%$ e $19,67 \%$ de proteína, 0,86\% e 3,73\% para lipídeo, 2,96\% e 0,52\% para carboidrato e valor energético de $101,63 \mathrm{Kcal} / 100 \mathrm{~g}$ e 114,39 Kcal/100g respectivamente, para pintado amazônico e piauçu. Não houve diferença ( $p>0,05$ ) para os parâmetros umidade, cinzas, proteína e carboidratos, sendo que os valores de lipídeo e valor energético foram maiores para o piauçu $(p<0,05)$. No teste de aceitação, não houve diferença $(p>0,05)$ para os atributos de aroma, textura, suculência e impressão global. Para os atributos de aparência, cor e sabor melhores resultados foram observados para o pintado amazônico ( $p<0,05)$, que também apresentou melhores escores para intenção de compra. Sendo assim, pode-se concluir que o piauçu apresentou maior teor de lipídeos e valor energético que o pintado amazônico e em relação à aceitação e intenção de compra de consumidores a carne do pintado amazônico apresentou melhores escores que o piauçu.
\end{abstract}

Palavras-chave: aceitação, composição centesimal, peixe, sensorial

\begin{abstract}
The objective of the work was to characterize the centesimal composition and the acceptance and intention to buy the Amazonian pintado (Pseudoplatystoma fasciatum X Leiarius marmoratus) and piauçu (Leporinus macrocephalus). Six specimens of the Amazonian pintado and eight of the Piauçu were obtained. The content of moisture, ash, proteins, lipids, carbohydrates and energy value were analyzed. The acceptance test was conducted using a nine-point hedonic scale and the buy intention using a five-point scale. The mean values of centesimal composition found were $74.67 \%$ and $74.90 \%$ for moisture, $0.99 \%$ and $1.16 \%$ ash, $20.49 \%$ and $19.67 \%$ protein, $0.86 \%$ and $3.73 \%$ for lipid, $2.96 \%$ and $0.52 \%$ for carbohydrate and energy value of $101.63 \mathrm{Kcal} / 100 \mathrm{~g}$ and $114.39 \mathrm{Kcal} / 100 \mathrm{~g}$ respectively, for the Amazon pintado and Piauçu. There was no difference $(p>0.05)$ for the parameters moisture, ash, protein and carbohydrates, and lipid and energy values were higher for piauçu $(p<0.05)$. In the acceptance test, there was no difference $(p>0.05)$ for aroma, texture, juiciness and overall impression attributes. For the attributes of appearance, color and flavor, better results were observed for the Amazonian pintado $(p<0.05)$, which also presented better scores for purchase intention. Thus, it can be concluded that piauçu had a higher content of lipids and energy value than the Amazonian pintado and in relation to the acceptance and intention to buy consumers the meat of the Amazonian pintado presented better scores than piauçu.
\end{abstract}

Keywords: acceptance, proximate composition, fish, sensory

\footnotetext{
*Recebido em 24 de agosto de 2015 e aceito em 14 de novembro de 2017.

**Instituto Federal de Educação, Ciência e Tecnologia de Mato Grosso, Mato Grosso, Brasil e doutores pelo Programa de Pós-Graduação em Medicina Veterinária - Universidade Federal Fluminense. Niterói, Rio de Janeiro, Brasil. Autora para correspondencia: marilulanzarin@yahoo.com.br.

***Universidade Federal de Mato Grosso. Faculdade de Agronomia, Medicina Veterinária e Zootecnia. Departamento de Ciências Básicas e Produção Animal. Programa de Pós-Graduação em Ciência Animal. Cuiabá, Mato Grosso, Brasil.

****Universidade Federal Fluminense. Faculdade de Veterinária. Departamento de Tecnologia de Alimentos. Programa de Pós-Graduação em Medicina Veterinária. Niterói, Rio de Janeiro, Brasil.
} 


\section{Introdução}

O cultivo planejado de peixes dulcícolas começou a se destacar na agroindústria brasileira nas últimas décadas, sendo o pintado amazônico (Pseudoplatystoma fasciatum X Leiarius marmoratus) e o piauçu (Leporinus macrocephalus) espécies importantes para a aquicultura destacando-se no pintado amazônico a qualidade de sua carne e bom rendimento no processamento e o piauçu o alto potencial zootécnico, boa qualidade de carne e boa adaptação ao cultivo intensivo (BALDISSEROTTO; GOMES, 2013). Dados descritos pela FAO (2016) apontam o Brasil em décimo quarto lugar na produção de pescado cultivado, com uma contribuição total de 562,5 milhões de toneladas.

O Brasil detém uma das maiores ictiofaunas de água doce do planeta com grande diversidade de espécies destinadas também à criação em cativeiro. Contraditoriamente, ainda há carência de dados sobre a composição química e aceitabilidade das várias espécies que tem se destacado no mercado interno e externo como o pintado amazônico e piauçu.

O conhecimento da composição centesimal do pescado é de fundamental importância para a padronização dos produtos alimentares na base de critérios nutricionais, além de fornecer subsídios para auxiliar na formulação de rações, processamento e conservação do peixe (SIMÕES et al., 2007).

Devido à rapidez no julgamento da matéria-prima e do produto acabado e pela facilidade de execução, a análise sensorial é um dos parâmetros mais utilizados para avaliação da qualidade do pescado, sendo largamente empregada. A análise de aceitação possibilita a obtenção de informações importantes, refletindo o grau com que os consumidores gostam ou não de um determinado produto (WESTAD et al., 2004; LAWLES; HEYMANN, 2010). Este método auxilia na avaliação do grau de aceitação de um grupo de provadores, sendo muito utilizado devido à sua simplicidade, confiabilidade e validade dos resultados. Com isso é possível transformar dados subjetivos em objetivos e obter informações importantes do mercado consumidor de um determinado produto (STONE et al., 2012).

O objetivo deste trabalho foi avaliar a composição centesimal e a aceitação e intenção de compra de consumidores em relação à carne dos peixes pintado amazônico (Pseudoplatystoma fasciatum X Leiarius marmoratus) e piauçu (Leporinus macrocephalus).

\section{Material e métodos}

\section{Obtenção das amostras}

Foram obtidos seis exemplares de pintado amazônico (Pseudoplatystoma fasciatum $X$ Leiarius marmoratus) $(2,0 \pm$ $0,5 \mathrm{~kg}$ e $53 \pm 4 \mathrm{~cm}$ ) e oito exemplares de piauçu (Leporinus macrocephalus) $(1,5 \pm 0,5 \mathrm{~kg}$ e $38 \pm 3 \mathrm{~cm})$ de pisciculturas localizadas no Estado de Mato Grosso sendo encaminhados ao laboratório de Higiene e Tecnologia de Pescado na Universidade Federal de Mato Grosso. Em condições laboratoriais os peixes foram eviscerados, lavados com água clorada (5ppm) e estocados em caixas isotérmicas entre camadas de gelo até realização do teste de aceitação e intenção de compra. Para as análises de composição centesimal parte da musculatura do peixe foi retirada e congelada para posterior análise, com exceção da análise de umidade que foi realizada com o peixe fresco.

\section{Análise de Composição Centesimal e Valor Energético}

As análises químicas foram realizadas no tecido muscular (sem pele) previamente cominuídas e homogeneizadas. Foram realizadas três repetições.

Os procedimentos para avaliação de umidade, cinzas, proteínas e lipídeos foram realizados segundo as recomendações preconizadas pela AOAC (2012). A análise de umidade foi realizada pelo método de secagem direta em estufa a $105^{\circ} \mathrm{C}$ ou perda por dessecação e para o resíduo mineral fixo (cinzas) utilizou-se o método de incineração em forno mufla a $550^{\circ} \mathrm{C}$. As proteínas e os lipídeos foram obtidos pelos métodos de Kjedahl e extração direta em Soxhlet, respectivamente. Para umidade utilizou-se amostras frescas e, para as demais análises, amostras congeladas e descongeladas "over night" antes da análise. Os resultados obtidos das análises de umidade, cinzas, proteínas e lipídeos foram expressos em porcentagem.

A porcentagem de carboidratos foi calculada pela equação \% carboidratos $=100 \%$ - ( $\%$ proteínas $+\%$ lipídeos $+\%$ umidade + $\%$ cinzas). O valor energético foi determinado pela multiplicação da porcentagem de proteínas, lipídeos e carboidratos pelo respectivo valor energético de 4, 9 e $4 \mathrm{Kcal}$, sendo os resultados expressos em Kcals totais por $100 \mathrm{~g}$. Ambos foram obtidos de acordo com Merrill e Watt (1973).

\section{Análise Sensorial}

A avaliação sensorial foi realizada no peixe fresco, quatro horas após a obtenção dos exemplares nas pisciculturas e conduzida de acordo com a metodologia proposta por Stone et al. (2012) utilizando-se 72 provadores não treinados. O preparo das amostras consistiu na remoção da cabeça e cauda dos peixes, sendo a parte muscular sem pele envolta em papel alumínio, sem adição de sal e/ou condimentos, assada em um forno a $300^{\circ} \mathrm{C}$ por 60 minutos, sendo o cozimento monitorado pela aferição da temperatura no interior da porção muscular. Até o momento em que foram apresentadas aos julgadores, as amostras foram mantidas em banho-maria a $50^{\circ} \mathrm{C}$.

Após o preparo, as amostras $(10,0 \pm 0,5 \mathrm{~g})$ codificadas com números de três dígitos foram apresentadas em pratos descartáveis com um fundo de cor clara, de modo que os julgadores não treinados pudessem avaliar os atributos sensoriais de aparência, cor, sabor, textura, suculência, impressão global e aroma (amostra foi apresentada em um becker de vidro coberto com vidro relógio). O teste foi realizado em cabine individual provida de luz branca sendo servida água mineral e biscoito água e sal para limpar o palato e um formulário de avaliação sensorial contendo: a escala hedônica de nove pontos, com extremos que vão desde "desgostei extremamente" (1) a "gostei extremamente" (9) e a intenção de compra utilizando uma escala de cinco pontos, variando de "certamente compraria" (5) a "certamente não compraria" (1).

\section{Análise Estatística}

A análise estatística dos resultados da composição centesimal e teste de aceitação foram realizados pela análise de variância por meio do procedimento "General Analytical Models" do pacote estatístico "Statistical Analytical System" (SAS INSTITUTE, 1999). Para comparação entre as médias, foi utilizado o teste de Tukey, em nível de 5\% de significância. 


\section{Resultados e discussão}

Em relação à composição centesimal e valor energético, os valores médios para pintado amazônico ( $P$. fasciatum $X L$. marmoratus) e piauçu (L. macrocephalus) estão dispostos na Tabela 1.

Tabela 1: Valores médios e desvio padrão da composição centesimal e valor energético do pintado amazônico (Pseudoplatystoma fasciatum X Leiarius marmoratus) e piauçu (Leporinus macrocephalus)

\begin{tabular}{ccc}
\hline Parâmetros & Pintado Amazônico & Piauçu \\
\hline Umidade & $74,67 \% \pm 0,32 \mathrm{a}$ & $74,90 \% \pm 0,09 \mathrm{a}$ \\
Cinzas & $0,99 \% \pm 0,17 \mathrm{a}$ & $1,16 \% \pm 0,23 \mathrm{a}$ \\
Proteína & $20,49 \% \pm 1,82 \mathrm{a}$ & $19,67 \% \pm 0,47 \mathrm{a}$ \\
Lipídeo & $0,86 \% \pm 0,01 \mathrm{~b}$ & $3,73 \% \pm 0,26 \mathrm{a}$ \\
Carboidrato & $2,96 \% \pm 1,95 \mathrm{a}$ & $0,52 \% \pm 0,12 \mathrm{a}$ \\
Valor Energético & $101,63 \mathrm{Kcal} / 100 \mathrm{~g} \pm 0,69 \mathrm{~b}$ & $114,39 \mathrm{Kcal} / 100 \mathrm{~g} \pm 0,01 \mathrm{a}$ \\
\hline
\end{tabular}

Médias na mesma linha, seguidas de letras iguais não diferem estatisticamente entre si no teste Tukey $(p>0,05)$

Não foi observada diferença $(p>0,05)$ entre as espécies estudadas para os parâmetros de umidade, cinzas, proteína e carboidrato, enquanto que para lipídeo e valor energético foi observada diferença $(p<0,05)$, sendo que o piauçu apresentou maiores valores que o pintado amazônico.

A composição centesimal de peixes apresenta uma ampla variação, pois dependem diretamente da espécie, estação do ano, fatores ambientais, dieta, idade e sexo (Li et al., 2013). Segundo Yeganeh et al., (2012) as frações lipídicas e proteicas são as que apresentam maiores variações entre as espécies levando a variações também nos teores de umidade devido a relação inversa entre esses componentes. De forma geral, porém, o presente estudo não evidenciou maiores diferenças composicional entre as espécies, com exceção para lipídeos e valores energéticos. Estes resultados vão ao encontro do que descrevem Fountoulaki et al. (2003), que a variação na composição centesimal de peixes oriundos de cultivo refletem a composição da dieta, em especial na porção lipídica. Puwastien et al (1999) consideram que valores entre 17 e 22 g/100 de proteína observadas em peixes podem ser considerados elevados. Um conhecimento primário do teor proteico do pescado é fundamental para o entendimento das espécies estudadas, como potenciais alimentos a serem oferecidos à população.

Com relação ao teor de proteínas, em geral a porção muscular de peixe possui em torno de $20 \%$, valor observado no presente estudo, com média de $20,49 \%$ no pintado amazônico e $19,67 \%$ no piauçu. Resultados similares foram também relatados por Simões et al. (2007) com tilápia (Oreochromis niloticus), Ramos Filho et al. (2008) com pintado (Pseudoplatystoma coruscans), cachara (Pseudoplatystoma fasciatum), pacu (Piaractus mesopotamicus) e dourado (Salminus maxillosus) e Sant'Ana et al. (2010) com cachara (Pseudoplatystoma fasciatum).

O teor médio de umidade e cinzas no pintado amazônico foi de $74,67 \%$ e $0,99 \%$ e no piauçu foi de $74,90 \%$ e $1,16 \%$, respectivamente, sendo estes valores similares aos encontrados, em outras espécies, na literatura (SIMÕES et al., 2007; SANT'ANA et al., 2010; VIANA et al., 2013). De acordo com Contreras-Guzmán (1994) a fração de cinzas em peixes de água doce apresenta variações em quantidades que vão de 0,90 a $3,39 \%$ sendo este valor compatível ao valor de cinzas encontrado nas espécies estudadas. Com relação ao conteúdo de minerais, já é amplamente conhecido que a distribuição é bastante uniforme em todo o tecido muscular, mas que o cálcio é mais alto nos ossos e espinhas (PUWASTIEN et al., 1999).

Os valores médios de lipídeos do pintado amazônico e piauçu foram de $0,86 \%$ e 3,73\%, respectivamente $(p<0,05)$. Segundo Ogawa e Maia (1999) o teor de lipídeo apresenta uma maior variação em função do tipo de músculo corporal, sexo, idade, época do ano, habitat e dieta entre outros fatores. Essa variação no teor de lipídeos foi também observada por Ramos Filho et al (2008) e Viana et al. (2013).

Do ponto de vista nutricional a gordura pode apresentar-se benéfica, pois altos teores de ácidos graxos poli-insaturados presente na carne dos peixes asseguram melhor digestão e rápida assimilação pelos tecidos dos organismos (OGAWA; MAIA, 1999).

Segundo Pigott e Tucker (1990), uma forma de definir a classificação de peixes está baseada na seguinte relação: menor que $2 \%$ de conteúdo de lipídeos, é um pescado de baixo conteúdo de gordura; entre 2 e $5 \%$, é um pescado moderado em conteúdo de gordura; e maiores que $5 \%$, é considerado um pescado com alto conteúdo de gordura. Os resultados classificam o pintado amazônico como um pescado com baixo teor de gordura e o piauçu como um pescado com moderado teor de gordura.

O valor médio de carboidratos foi de 2,96\% para pintado amazônico e 0,52\% para o piauçu. Em relação a esta última espécie, o resultado se assemelha aos valores propostos por Ogawa e Maia (1999), para peixes em geral. Porém, os teores de carboidratos do pintado amazônico se apresentaram em proporção elevada, provavelmente em função do tipo e da qualidade de ração recebida no tanque.

O valor energético médio no músculo do pintado amazônico $(101,63 \mathrm{Kcal} / 100 \mathrm{~g})$ foi inferior ao valor do piauçu $(114,39$ $\mathrm{Kcal} / 100 \mathrm{~g})(p<0,05)$. Resultado semelhante ao deste estudo foi observado por Caula et al. (2008) em músculos de curimatã (Prochilodus cearensis) e sardinha (Triportheus angulatus) que apresentaram valor calórico de 108,4 Kcal/100g e 111,8 $\mathrm{Kcal} / 100 \mathrm{~g}$, respectivamente.

$\mathrm{Na}$ tabela 2 estão discriminados os valores médios do teste de aceitação quanto à aparência, cor, aroma, sabor, textura, suculência e impressão global do pintado amazônico ( $P$. fasciatum X L. marmoratus) e piauçu (L. macrocephalus). De acordo com os dados da tabela 2, não houve diferença $(p>0,05)$ para os atributos de aroma, textura, suculência e impressão global entre as espécies avaliadas, entretanto, a espécie pintado amazônico apresentou maiores escores de aparência, cor e sabor quando comparado à espécie piauçu $(p<0,05)$. 
Tabela 2: Valores médios do teste de aceitação quanto à aparência, cor, aroma, sabor, textura, suculência e impressão global do pintado amazônico (Pseudoplatystoma fasciatum X Leiarius marmoratus) e piauçu (Leporinus macrocephalus)

\begin{tabular}{lccccccc}
\hline Peixe & Aparência & Cor & Aroma & Sabor & Textura & $\begin{array}{c}\text { Suculência } \\
\text { Impressão } \\
\text { Global }\end{array}$ \\
\hline Pintado & $7,53 \pm 1,03 \mathrm{a}$ & $7,46 \pm 1,55 \mathrm{a}$ & $6,95 \pm 1,42 \mathrm{a}$ & $7,53 \pm 1,43 \mathrm{a}$ & $7,54 \pm 1,17 \mathrm{a}$ & $7,43 \pm 1,31 \mathrm{a}$ & $7,56 \pm 1,04 \mathrm{a}$ \\
\hline Piauçu & $7,03 \pm 1,52 \mathrm{~b}$ & $6,83 \pm 1,53 \mathrm{~b}$ & $6,75 \pm 1,58 \mathrm{a}$ & $7,01 \pm 1,46 \mathrm{~b}$ & $7,33 \pm 1,08 \mathrm{a}$ & $7,25 \pm 1,45 \mathrm{a}$ & $7,22 \pm 1,53 \mathrm{a}$ \\
\hline
\end{tabular}

Médias na mesma coluna, seguidas de letras iguais não diferem estatisticamente entre si no teste Tukey $(p<0,05)$

As amostras de pintado amazônico e piauçu cozidas obtiveram valores médios de aceitação entre 7,0 e 8,0 para os atributos aparência, sabor, textura, suculência e impressão global, na qual estão situados os termos hedônico "gostei moderadamente" e "gostei muito", respectivamente, fato este também observado no estudo de Barbosa et al. (2008) que avaliaram a aceitação sensorial da espécie dulcícola tilápia do Nilo (Oreochromis niloticus) e obtiveram médias de aceitação de 7,1 indicando que estas matrizes alimentícias apresentam boa aceitação pelos consumidores o que confirma a importância destas espécies para a aquicultura brasileira já que apresentam boa aceitabilidade pelos consumidores. Enquanto que Borges et al. (2013) ao estudarem as espécies dulcícolas pacu (Piaractus mesopotamicus), tambaqui (Colossoma macropomum) e tambacu (Colossoma macropomum $X$ Piaractus mesopotamicus) observaram médias de aceitação entre 5,0 e 7,0,

Apesar dos valores médios da aceitação dos atributos aroma, textura, suculência e impressão global de ambas as espécies terem sido próximos, na avaliação de intenção de compra (somatória dos termos de atitude positiva para compra contida na ficha de avaliação) o pintado amazônico apresentou melhor resultado com $85,46 \%$ em relação ao

\section{Referências}

AOAC (ASSOCIATION OF OFFICIAL ANALYTICAL CHEMISTS). Official methods of analysis of the Association of Official Analytical Chemists. 19.ed. Arlington: AOAC International, 2012.

BALDISSEROTTO, B. e GOMES, L. C. Espécies nativas para piscicultura no Brasil. 2a ed. Santa Maria: Editora da UFSM, 2013.

BARBOSA, A. C. B., CARNEIRO, P. L. S., MALHADO, C. H. M., AFFONSO, P. R. A. M.; CARNEIRO, J. C. S.; ROCHA, L. G.; CARNEIRO, J. D. S. Desempenho e Avaliação Sensorial de Duas Linhagens de Tilápia do Nilo. Revista Científica Produção Animal, v.10, n.1, p. 5008-59, 2008.

BORGES, A.; MEDINA, B. G.; CONTE-JÚNIOR, C. A.; FREITAS, M. Q. Aceitação sensorial e perfil de textura instrumental da carne cozida do pacu, do tambaqui e do seu híbrido tambacu eviscerados e estocados em gelo. Revista Brasileira de Ciência Veterinária, v.20, n.3, p.160-165, 2013.

CAULA, F. C. B.; OLIVEIRA, M. P.; MAIA, E. L. Teor de colesterol e composição centesimal de algumas espécies de peixes do estado do Ceará. Ciência e Tecnologia de Alimentos, v.28, p.959963, 2008.

CONTRERAS-GUZMÁN, E. S. Bioquímica de pescados e derivados. Jaboticabal: FUNEP; 1994.

FAO. Fisheries and Aquaculture topics. Fisheries statistics and information. Topics Fact Sheets. In: FAO Fisheries and Aquaculture Department. Rome, 2016. piauçu que obteve $69,34 \%$ de provadores que comprariam, fato este que pode ser explicado devido à espécie piauçu apresentar menores escores em relação à aparência, cor e sabor $(p<0,05)$ quando comparado ao pintado amazônico, além da espécie ser provida de espinhos, ao contrário do pintado amazônico, sendo que esta característica foi observada e registrada como comentários pelos julgadores.

\section{Conclusão}

Pode-se concluir que ambas as espécies apresentaram indicadores que os caracterizam como alternativa viável como fonte de macronutrientes para consumo alimentar, sendo que o piauçu apresentou maior teor de lipídeos e valor energético que o pintado amazônico. A aceitação e intenção de compra de consumidores em relação à carne do pintado amazônico apresentaram melhores escores que o piauçu. Estudos que disponibilizem dados em peixes com potencial comercial de áreas com tradição no consumo de peixes frescos e congelados são de extrema relevância.

FOUNTOULAKI, E.; ALEXIS, M. N.; NENGAS, I.; VENOU, B. Effects of dietary arachidonic acid (20:4n-6), on growth, body composition, and tissue fatty acid profile of gilthead bream fingerlings (Sparus aurata L.). Aquaculture. n.225, p.309-323, 2003.

LAWLESS, H.T.; HEYMANN, H. Sensory evaluation of food: principles and practices. $2^{\mathrm{a}}$ ed. New York: Springer, 2010.

LI, T.; LI, J.; HU, W. Changes in microbiological, physicochemical and muscle proteins of post mortem large yellow croaker (Pseudosciaena crocea). Food Control, v. 34, p. 514-520, 2013.

MERRILL, A.L; WATT, B.K. Energy value of foods: basis and derivation. Washington, DC ARS USDA: Agriculture Handbook, n. 74, $1973.105 \mathrm{p}$.

OGAWA, M. e MAIA, E. L. Manual de pesca - ciência e tecnologia do pescado. São Paulo: Varela, v.4, p. 29-71, 1999.

PIGOT, G; TUCKER, B. Sea food effects of technology on nutrition, 1stedit, Edit Marcel Dekker, INC, New York, USA, 1990.

PUWASTUEN, P.; JUDPRASONG, K.; KETTWAN, E.;

VASANACHITT, K.; NAKNGAMANONG, Y.; BHATTACHARJEE, L. Proximate composition of raw and cooked thai freshwater and marine fish. Journal of food composition and analysis, v.12, p.916, 1999.

RAMOS FILHO, M. M.; RAMOS, M. I. L.; HIANE, P. A.; SOUZA, M. T. Perfil lipídico de quatro espécies de peixes da região pantaneira de Mato Grosso do Sul. Ciência e Tecnologia de Alimentos, v.28, p.361-365, 2008. 
SANT'ANA, L. S.; DUCATTI, C.; RAMIRES, D. G. Seasonal variations in chemical composition and stabla isotopes of farmed and wild Brazilian freshwater fish. Food Chemistry, v.122, p.7477, 2010.

SAS INSTITUTE. SAS user's guide. 6.04 Edition. Cary, NC., 1999. 956p.

STONE, H.; BLEIBAUM, R. N.; THOMAS, H. A. Sensory evaluation practices. 4 ed. San Diego: Academic Press, 2012. 438 p. SIMÕES, M.; RIBEIRO, C.F.A; RIBEIRO, S.C.A; PARK K.J; MURR F.E.X. Physicochemical and microbiological composition and yield of thai-style tilapia fillets (Oreochromis niloticus). Ciência e Tecnologia de Alimentos. v.27, p.608-13, 2007.
VIANA, Z. C. V.; SILVA, E.; FERNANDES, G. B.; SANTOS, V. L. C. S. Composição centesimal em músculo de peixes no litoral de estado da Bahia/Brasil. Revista Ciências Médicas e Biológicas, v.12, n.2, p.157-162, 2013.

WESTAD, F.; HERSLETH, M.; LEA, P. Strategies for consumer segmentation with application on preference data. Food Quality and Preference, v.15, n. 2, p.681-687, 2004.

YEGANEH S.; SHABANPOUR B.; HOSSEINI H.; IMANPOUR, M.R.; SHABANI A. Comparison of farmed and wild common carp (Cyprinus carpio): Seasonal variations in chemical composition and fatty acid profile. Czech Journal of Food Sciences, n. 30, p.503-511, 2012. 